\title{
Impactos costeiros induzidos por ondas de tempestade entre o Cabo Frio e o Cabo Búzios, Rio de Janeiro, Brasil
}

\author{
Coastal impacts induced by storm waves between Cape Frio and Cape \\ Buzios, Rio de Janeiro, Brazil
}

\section{Eduardo Manuel Rosa Bulhões ${ }^{\text {ad }}$, Guilherme Borges Fernandez ${ }^{\text {ce }}$, Silvio Roberto de Oliveira Filho $^{\text {af }}$, Thiago Gonçalves Pereira ${ }^{\text {bg }}$, Thaís Baptista da Rocha ${ }^{\text {ch }}$}

\begin{abstract}
a Laboratório de Geografia Física, Departamento de Geografia, Instituto de Ciências da Sociedade e Desenvolvimento Regional,

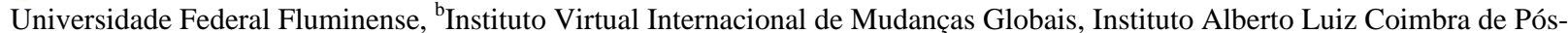
Graduação e Pesquisa de Engenharia, Universidade Federal do Rio de Janeiro, 'aboratório de Geografia Física, Programa de Pós Graduação em Geografia, Instituto de Geociências, Universidade Federal Fluminense

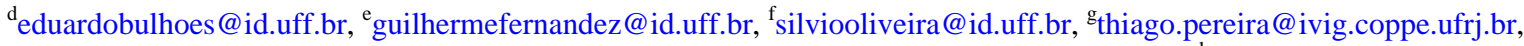
hthaisitc5@yahoo.com.br,
\end{abstract}

\begin{abstract}
Resumo
O campo de ondas em águas profundas é notável por sua variabilidade e dita a energia de ondas que vai ser direcionada para a costa. Os impactos morfológicos nos ambientes costeiros dependem da magnitude das forçantes meteorológicas e oceanográficas e da capacidade das praias de absorverem esta energia. Na análise entre o Cabo Frio e o Cabo Búzios, foram consideradas as características texturais da plataforma continental interna a partir da análise de 394 amostras, a variabilidade volumétrica de 438 levantamentos ao longo de 17 perfis de praia e as características de 69 tempestades entre 2003 e 2013. Os resultados apontaram que a sedimentação na zona submarina proximal reflete, através do parâmetro diâmetro médio dos grãos, as áreas com maior ou menor energia de ondas. Os resultados apontaram também a ocorrência de uma "temporada de ondas de tempestade" - principal elemento associado à erosão do estoque subaéreo das praias - entre abril e setembro, e que um período com ausência dessas ondas tende a ocorrer recuperação. Os diferentes segmentos de praia analisados mostraram maior ou menor magnitude desses efeitos, em função basicamente da orientação e exposição relativa de cada segmento de praia. Tempestades isoladas com maior magnitude tendem a promover erosão severa, sobretudo se ocorrerem no início da "temporada de ondas de tempestade".
\end{abstract}

Palavras-chave: Ondas de Tempestade; Perfis de Praia; Sedimentos Costeiros; Cabo Búzios; Cabo Frio.

\begin{abstract}
The wave field in deep waters is notable for its variability and dictates the energy that will be directed towards the coast. Morphological impacts on coastal environments depend on the magnitude of the meteorological and oceanographic forcings and the beach capabilities of absorbing this energy. In the analysis between Cape Frio and Cape Buzios, we considered the textural characteristics of the inner continental shelf from the analysis of 394 samples, the volumetric variability of 438 surveys along 17 beach profiles and characteristics of 69 storms between 2003 and 2013. Results showed that sedimentation in the nearshore, through the mean grain size parameter, reflects the areas with higher or lower wave energy. The results also indicated the occurrence of a "storm waves season" between April and September, and this is the main element associated with erosion of subaereal stock on beaches. A period with no occurrence of these storm waves the recovery of this subaereal sandy stock tend to occur. The different segments of beach show the greater or lesser magnitude of these effects, depending primarily on the orientation and exposure of each beach segment. Isolated storms with greater magnitude tend to promote severe erosion, especially if they occur at the beginning of this "season of storm waves".
\end{abstract}

Keywords: Storm Waves; Beach Profiles; Coastal Sediments; Cape Buzios; Cape Frio.

\section{Introdução}

O campo de ondas em águas profundas é particularmente notável por sua variabilidade e dita a energia de ondas que será direcionada para a costa (Komar 1976, Hallermeier 1981). Estudos de processos dinâmicos no litoral e mesmo de evolução do relevo costeiro usam como elemento caracterizador a energia 
Papel da praia na proteção da costa e as alterações oceanográficas em diferentes escalas temporais

dispensada pelas ondas na linha de costa, já que essas vêm sendo reconhecidas na literatura desde o clássico trabalho de Douglas Wilson Johnson em 1919, ou mesmo antes, como a principal forçante da morfologia costeira.

Sob o ponto de vista geomorfológico, os impactos morfológicos nos ambientes costeiros dependem, em primeira instância, da magnitude das forçantes meteorológicas e oceanográficas, mais especificamente na formação de marulhos (swell) e vagas (seas), e, em segunda instância, da capacidade das praias em absorverem essa energia. No litoral centro-norte do Rio de Janeiro, mais especificamente entre os municípios de Arraial do Cabo e Armação dos Búzios (figura 01), a presença de promontórios rochosos segmenta o litoral em praias de enseada com orientações, exposições, características morfológicas e morfodinâmicas distintas. Distintos são também os impactos e as alterações morfológicas (erosão, transporte e deposição de sedimentos) produzidos nas enseadas pelas ondas de tempestade alternadas pelas ondas de tempo bom, e este é o tema central a ser desenvolvido neste artigo.

\subsection{Praias de Enseada}

Praias de enseada, por definição, são ambientes arenosos bordeados por margens rochosas ou artificiais que assumem uma curvatura definida em função da disponibilidade de sedimentos e do padrão de circulação hidrodinâmica induzido por ondas. Na natureza, são caracterizadas por ocorrerem como ambientes encaixados entre promontórios rochosos préexistentes.

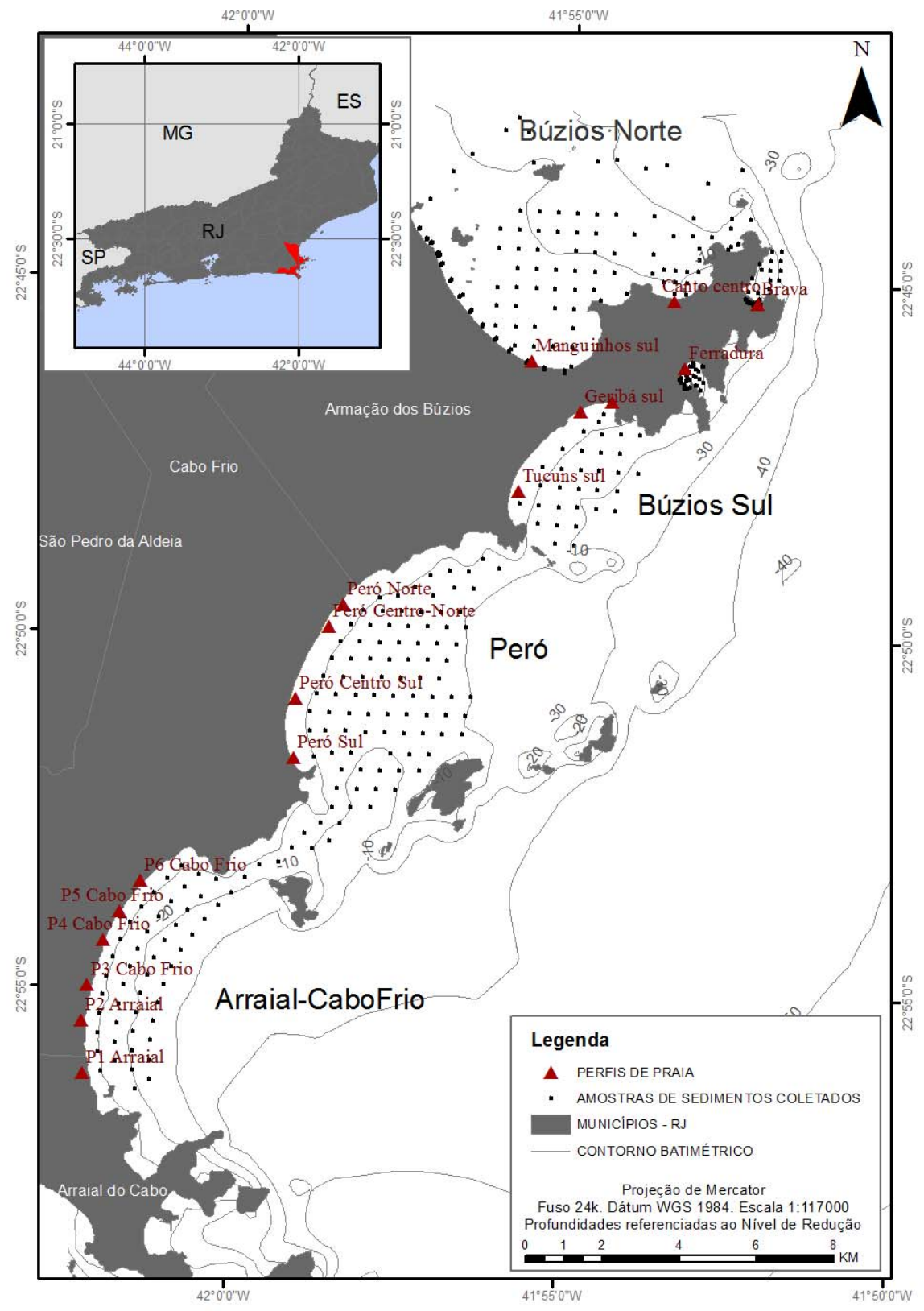

Figura 01: Área de Estudo, posição dos perfis, contornos batimétricos e malha amostral de sedimentos. 
Papel da praia na proteção da costa e as alterações oceanográficas em diferentes escalas temporais

Jackson et al. (2005) resgatam a idéia de que todas as praias estão apoiadas sobre uma estrutura geológica antecedente e é essa estrutura que determina os limites pelos quais a praia se forma e se espacializa. Os processos hidrodinâmicos que irão influenciar a dinâmica dos ambientes praiais podem ser controlados pela disposição desta estrutura geológica, como a presença de costões rochosos, ilhas, lajes submersas etc. Short (1999) acrescenta que, apesar da estrutura rochosa ser totalmente independente dos processos de formação das praias, exerce papel fundamental no formato em planta, no transporte de sedimentos e nos aspectos morfodinâmicos das praias que abrigam.

Mahiques et al. (1998) consideram que (i) a interação entre a direção de incidência das ondas, com (ii) a extensão e orientação das aberturas das enseadas, e ainda, (iii) a presença de ilhas ou lajes rochosas na plataforma continental interna, levam à ocorrência de variações na dinâmica das enseadas. As diferenças nos níveis de energia entre as enseadas estão associadas à direção de incidência das ondas e à orientação das aberturas delas. Ainda segundo os autores, os dados de distribuição de sedimentos de fundo revelam a possibilidade de se estabelecer um gradiente de energia dos agentes hidrodinâmicos que agem sobre a superfície do fundo de determinada enseada. No mesmo sentido, Loureiro et al. (2009) e Bulhões et al. (2013) mostram que a maior diferença nos impactos morfológicos sofridos por praias de enseada durante eventos de tempestade está associada à posição relativa destas às entradas das frentes de onda.

\subsection{Eventos de Tempestade e Alteração Morfológica da Linha de Costa}

A ciclogênese é definida como o desenvolvimento ou o ganho de energia de sistemas ciclônicos que, em latitudes médias, são chamados de ciclones extratropicais. De acordo com Innocentini et al. (2003), a agitação marítima mais intensa que ocorre no Atlântico Sul é ocasionada pelos ciclones migratórios, cujo deslocamento, de acordo com Satyamurty \& Mattos (1989), segue o sentido SW - NE.

Parise et al. (2009) descrevem três padrões de trajetórias das tempestades sobre o sudoeste do Atlântico baseados no mínimo de vorticidade relativa no centro de ciclones: a) ciclogênese ao sul da Argentina com deslocamento para leste e trajetória entre $47.5^{\circ} \mathrm{S}$ e $57.5^{\circ} \mathrm{S}$; b) ciclogênese ao sul do Uruguai com deslocamento para leste e trajetória entre $35^{\circ} \mathrm{S}$ e $42.5^{\circ} \mathrm{S}$; e c) ciclogênese ao sul do Uruguai com deslocamento para sudeste e trajetória entre $35^{\circ} \mathrm{S}$ e $57.5^{\circ} \mathrm{S}$. Adicionalmente, Reboita et al. (2005) apud Parise (2010) identificam atividade ciclogenética na costa sul e sudeste do Brasil, situada entre $20^{\circ} \mathrm{S}$ e $35^{\circ} \mathrm{S}$, sendo essa última mais próxima ao litoral fluminense.

Nas zonas costeiras, os eventos de tempestade têm sido caracterizados na literatura a partir do momento que a altura significativa das ondas $\left(H_{\mathrm{s}}\right)$ ultrapassa 0 limiar de 3 metros (You \& Lord 2008, Loureiro et al. 2009, Jacob et al. 2009) por mais de 12 horas (Rangel-
Buitrago \& Anfuso 2011, Santiago et al. 2013). Nesse sentido, dados de saída (altura significativa da onda, direção média de ondas, período de pico, velocidade do vento e direção média dos ventos) do modelo WaveWatch III (WW3), compilados entre 2003 e 2013 para a posição ao largo do Cabo Búzios, mostram o total de eventos e algumas características das tempestades, sumarizados na tabela 1 .

Tabela 1: Distribuição e Características Médias dos Eventos de Tempestade entre 2003 e 2013. Fonte: Modelo WW3.

\begin{tabular}{|c|c|c|c|c|c|}
\hline Ano & $\begin{array}{c}\text { Total de } \\
\text { Eventos de } \\
\text { Tempestade }\end{array}$ & $\begin{array}{c}\text { Duração } \\
\text { Média (h) }\end{array}$ & $\begin{array}{l}\text { Altura Média } \\
\text { das Ondas (m) }\end{array}$ & 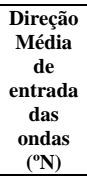 & $\begin{array}{c}\text { Altura } \\
\text { Máxima de } \\
\text { Ondas (m) }\end{array}$ \\
\hline 2003 & 6 & 30 & 3,00 & 180,00 & 3,00 \\
\hline 2004 & 11 & 34 & 3,00 & 180,00 & 3,00 \\
\hline 2005 & 3 & 54 & 3,00 & 180,00 & 3,00 \\
\hline 2006 & 10 & 43 & 3,24 & 178,82 & 4,00 \\
\hline 2007 & 9 & 39 & 3,17 & 180,00 & 4,00 \\
\hline 2008 & 9 & 32 & 3,00 & 172,29 & 3,00 \\
\hline 2009 & 9 & 32 & 3,00 & 180,00 & 3,00 \\
\hline 2010 & 3 & 48 & 3,13 & 167,14 & 4,00 \\
\hline 2011 & 5 & 37 & 3,08 & 176,25 & 0,00 \\
\hline 2012 & 0 & - & - & - & - \\
\hline 2013 & 4 & 32 & 3,33 & 189,64 & 4,00 \\
\hline total & 69 & 38 & 3,09 & 178,41 & 2,82 \\
\hline Mês & $\begin{array}{c}\text { Total de } \\
\text { Eventos de } \\
\text { Tempestade }\end{array}$ & Mês & $\begin{array}{c}\text { Total de } \\
\text { Eventos de } \\
\text { Tempestade }\end{array}$ & Mês & $\begin{array}{c}\text { Total de } \\
\text { Eventos de } \\
\text { Tempestade }\end{array}$ \\
\hline Jan & 1 & Mai & 11 & Set & 9 \\
\hline Fev & 1 & Jun & 9 & Out & 3 \\
\hline Mar & 1 & Jul & 7 & Nov & 7 \\
\hline Abr & 7 & Ago & 11 & Dez & 2 \\
\hline
\end{tabular}

De acordo com Davis Jr. (1985), as tempestades excepcionais representam um dos principais elementos de alteração morfológica em curto período de feições costeiras submetidas à ação das ondas. Para descrever tais eventos, é feita uma categorização em função de parâmetros como tempo (duração) de ocorrência, altura significativa e máxima das ondas, direção e intensidade dos ventos e, principalmente, efeitos resultantes na linha de costa. Em relação às tempestades na costa americana, Dolan \& Davis (1992) formularam, a partir de análises de sistemas frontais do quadrante Nordeste (NE), uma classificação em mesoescala direcionada aos efeitos morfológicos na linha de costa. Esses efeitos foram sumarizados por Sallenger (2000) e Morton \& Sallenger (2003), que identificaram elementos de alteração morfológica entre feições erosivas e deposicionais. As três feições erosivas identificadas foram: erosão de dunas frontais, incisão de canais e washouts. Bulhões et al. (2010) e Fernandez et al. (2011) descreveram esses efeitos e evidenciaram erosão de praia e de dunas, recuo de escarpa erosiva e abertura de barra lagunar nas praias do litoral centro-norte fluminense durante uma tempestade em abril de 2010.

O objetivo central deste artigo é diagnosticar o comportamento morfológico de perfis de praia selecionados nas enseadas entre o Cabo Frio e o Cabo Búzios (RJ), e mostrar que a exposição ou proteção relativa de cada segmento deste litoral frente à entrada de ondas de tempestade é o principal elemento controlador dessas alterações. 
Papel da praia na proteção da costa e as alterações oceanográficas em diferentes escalas temporais

\section{Materiais e Métodos}

Para atender ao objetivo proposto, foram compiladas informações acerca de levantamentos de perfis de praia em 17 posições entre o município de Arraial do Cabo e Armação dos Búzios, Rio de Janeiro. No total, foram utilizados 438 levantamentos topográficos realizados entre 2005 e 2013 por vários colaboradores do Laboratório de Geografia Física da Universidade Federal Fluminense - em maior parte já publicados em trabalhos de Pereira et al. (2007), Pereira (2008), Bulhões (2011) e Oliveira Filho (2011) - e, para cada um deles, calculado o volume da porção emersa do perfil praial.

A variação volumétrica da porção emersa dos perfis praiais ao longo do tempo visa evidenciar a flutuação do estoque sedimentar que compõe a morfologia dos perfis.

Adicionalmente, foram compiladas informações de levantamentos de sedimentos da superfície do fundo na plataforma continental interna entre o Cabo Frio e o Cabo Búzios. No total, foram analisadas 394 amostras, coletadas entre 2008 e 2011, na plataforma continental interna adjacente à área de estudo, sendo 50 adjacentes à linha de costa do arco Arraial-Cabo Frio, 99 adjacentes ao arco Peró, e 245 representando as enseadas do Cabo Búzios. Todas as análises de sedimentos seguiram as classes propostas por Wentworth (1922), através do método do peneiramento a seco, excetuando-se as 38 amostras siltosas ao norte do Cabo Búzios que foram analisadas por difratometria laser. Os resultados foram compilados com o objetivo de avaliar se as áreas de maior energia de ondas corroboram com a variação granulométrica de fundo.

Por fim, foram realizadas simulações de distribuição de energia de ondas em águas rasas para as principais entradas de ondas de tempestade. Para tal, foram identificadas 69 tempestades entre abril de 2003 e dezembro de 2013 (tabela 1) para a posição (24\%'S, $41^{\circ} 40^{\prime} \mathrm{W}$ ) que atendiam à padronização de ondas maiores que 3 metros ocorrendo por um período mínimo de 12 horas. A partir desta identificação das tempestades, foram utilizados os valores de altura significativa máxima acrescidos do desvio padrão e período de pico máximo. Foram simuladas essas condições para três direções distintas: a direção média, a direção média menos o desvio padrão e a direção média mais o desvio padrão da entrada de ondas de tempestade. Os dados de vento utilizados foram os das condições médias.

\section{Resultados e Discussão}

\subsection{Distribuição de Sedimentos de Fundo}

Os resultados do diâmetro médio dos sedimentos (figuras 02 e 03) indicam que a ocorrência de sedimentos finos é predominante (63\%). Eles ocorrem na classe das areias finas (43\%) e muito finas (5\%) ao sul da área de estudo, enquanto ao norte há ocorrência das classes silte grosso (6\%), silte médio (4\%) e silte fino (5\%). Estes resultados representam duas fontes distintas de sedimentação para a área de estudo, conforme já sugerido por Saavedra (1994). Ao sul (Arcos Arraial-Cabo Frio e Peró), trata-se de areias reliquiares da plataforma continental interna que abastecem as praias e os campos de dunas ao longo destes arcos. Ao norte do Cabo Búzios, os siltes representam uma sedimentação fluvial neotérica (moderna) de origem fluvial que recobre as areias palimpsestas (Bulhões \& Fernandez 2011).

$\mathrm{Na}$ porção central das enseadas e nas proximidades dos promontórios rochosos, ocorrem manchas de sedimentos mais grossos, como as areias médias (22\%), tanto no arco praial Arraial-Cabo Frio quanto no arco praial Peró, e as areias grossas (10\%) e muito grossas (6\%) ao norte e ao sul do Cabo Búzios. As areias grossas indicam, ao norte do Cabo Búzios, maior agitação promovida por ondas, impossibilitando a sedimentação fina (siltosa) neotérica de se depositar, conforme resultados de Tavares et al. (2010).

Ao sul do Cabo Búzios, os sedimentos grossos indicam áreas cascalhosas de fragmentos majoritariamente biodetríticos, sobretudo na proximidade dos promontórios rochosos e lajes rochosas submersas. No arco praial Peró, trabalhos publicados por Guerra et al. (2005), Muehe et al. (2010) e Oliveira Filho (2011) encontraram resultados semelhantes entre si, tais como: sedimentos médios na porção central do arco praial e redução do diâmetro médio em direção às extremidades da praia - padrão que se repete para a zona submarina proximal. As interpretações foram distintas: enquanto o primeiro autor atribuiu o padrão da distribuição granulométrica à convergência da deriva litorânea para a porção central, levando à acumulação de sedimentos; o segundo afirmou que a porção central do arco praial é uma área dispersora de sedimentos finos; já o terceiro autor considerou o efeito de difração de ondas em função do posicionamento das ilhas defronte ao arco praial para explicar esta distribuição de sedimentos. A despeito dessas interpretações e concordando que o agente deposicional principal é a circulação promovida por ondas, é importante considerar que o diâmetro médio do sedimento descreve a energia cinética média do agente deposicional (Sahu 1964) e, portanto, é um bom indicador da ação das ondas sobre as áreas mais rasas da plataforma continental. 
Quaternary and Environmental Geosciences (2014) 05(2):155-165

Papel da praia na proteção da costa e as alterações oceanográficas em diferentes escalas temporais

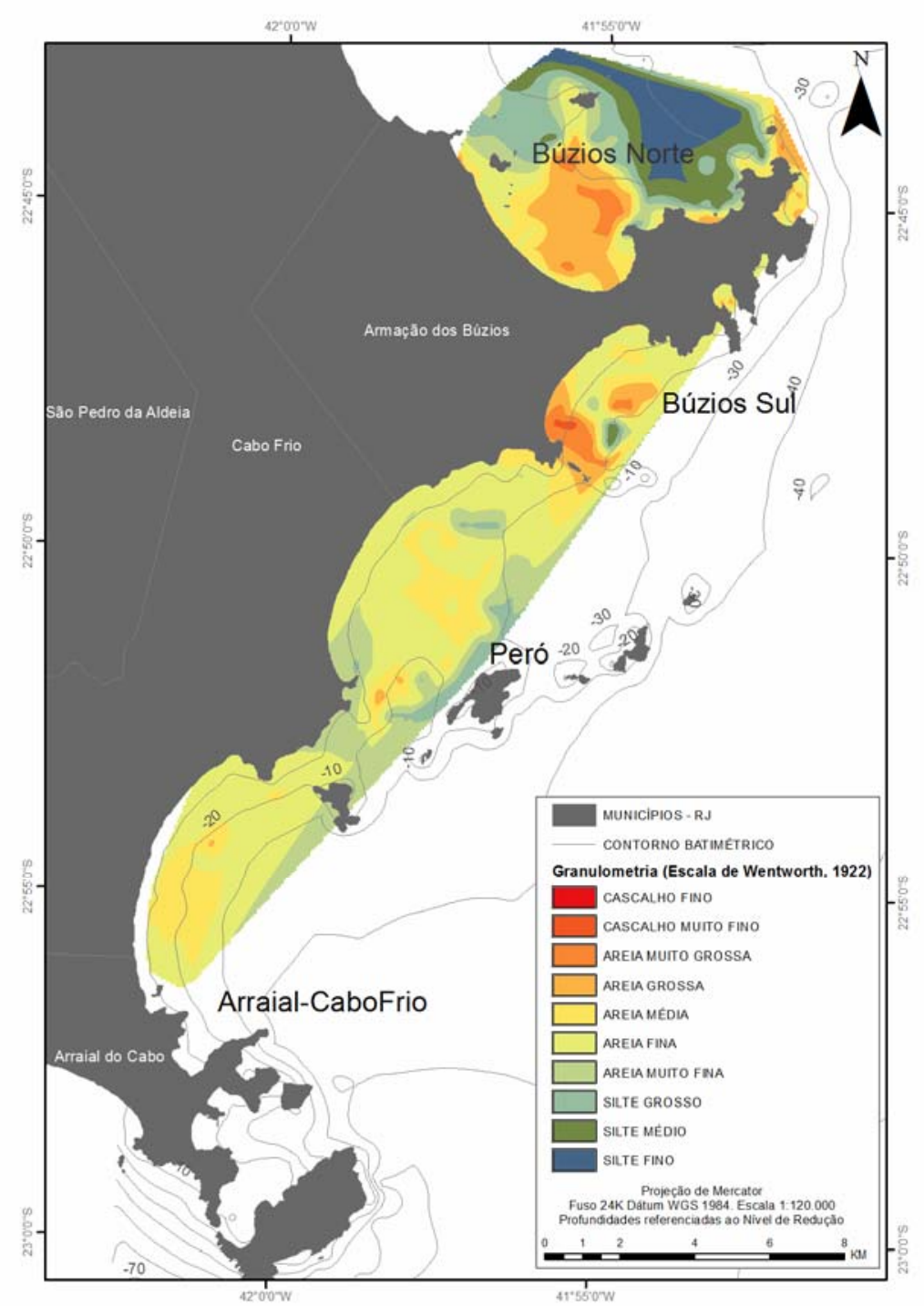

Figura 02: Diâmetro médio interpolado a partir de 394 amostras de sedimentos costeiros representando a antepraia e a plataforma continental interna entre o Cabo Frio e o Cabo Búzios.

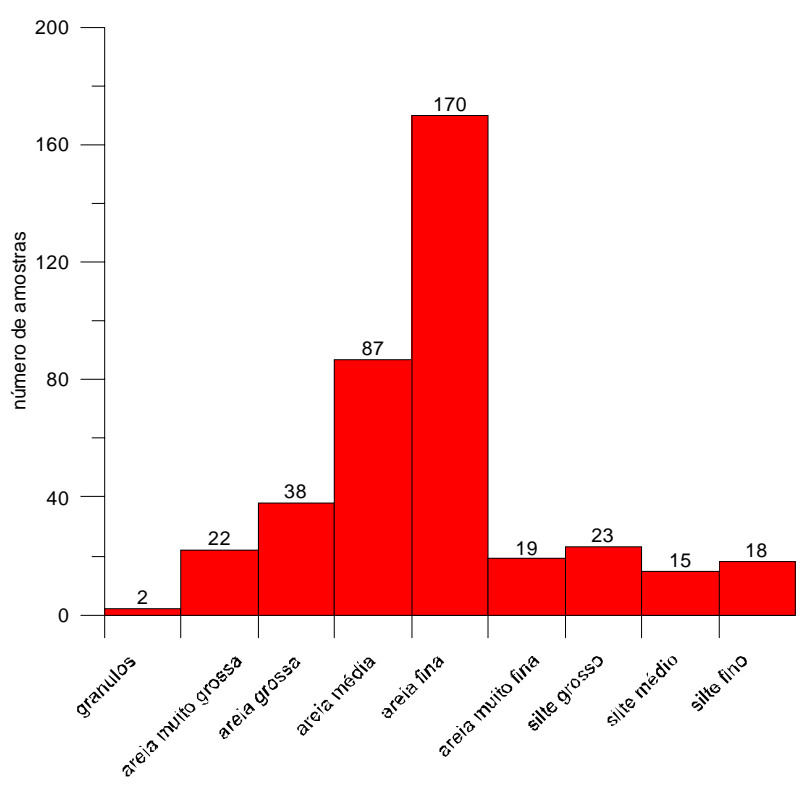

Figura 03: Histograma de distribuição das classes granulométricas das amostras analisadas entre o Cabo Frio e o Cabo Búzios. 
Papel da praia na proteção da costa e as alterações oceanográficas em diferentes escalas temporais

\subsection{Distribuição de Energia de Ondas}

A tabela 2 sumariza a estatística básica dos 69 eventos de tempestade identificados no período de 2003-2013.

Tabela 2: Estatística Básica para Ondas de Tempestade ao Largo da Área de Estudo Fonte: Modelo WW3

\begin{tabular}{ccccccc}
\hline $\begin{array}{c}\text { Características } \\
\text { dos Eventos de } \\
\text { Tempestade }\end{array}$ & $\begin{array}{c}\text { Altura } \\
\text { Sign. } \\
\text { Ondas } \\
(\mathbf{m})\end{array}$ & $\begin{array}{c}\text { Direção } \\
\left({ }^{\circ} \mathbf{N}\right)\end{array}$ & $\begin{array}{c}\text { Período } \\
\text { (s) }\end{array}$ & $\begin{array}{c}\text { Velocidade } \\
\text { do Vento } \\
(\mathbf{m} / \mathbf{s})\end{array}$ & $\begin{array}{c}\text { Direção } \\
\text { do } \\
\text { Vento } \\
\left({ }^{\mathbf{N}}\right)\end{array}$ & $\begin{array}{c}\text { Duração } \\
\text { (hs) }\end{array}$ \\
\hline Máxima & 4,7 & 247,5 & 16,0 & 27,0 & 337,5 & 105,0 \\
Média & 3,2 & 179,0 & 11,6 & 11,2 & 145,1 & 36,2 \\
Mínima & 2,2 & 112,5 & 6,0 & 1,0 & 0,0 & 18,0 \\
Desvio Padrão & 0,4 & 24,3 & 1,7 & 4,4 & 72,8 & 16,9 \\
\hline
\end{tabular}

Foram elaboradas três simulações hipotéticas de incidência de ondas com as seguintes características básicas de entrada:

- $\quad$ Simulação 01 - Altura significativa de ondas 5,1m; período de pico $16 \mathrm{~s}$; direção média de ondas $179^{\circ}$ (Sul); velocidade do vento 11 (m/s); direção média do vento $145^{\circ}$ (SuSudeste).

- $\quad$ Simulação 02 - Altura significativa de ondas 5,1m; período de pico 16s; direção média de ondas $154,7^{\circ}$ (Su-Sudeste); velocidade do vento $11(\mathrm{~m} / \mathrm{s})$; direção média do vento $145^{\circ}$ (Su-Sudeste).

- $\quad$ Simulação 03 - Altura significativa de ondas 5,1m; período de pico 16s; direção média de ondas 203,3 $3^{\circ}$ (Su-Sudoeste); velocidade do vento $11(\mathrm{~m} / \mathrm{s})$; direção média do vento $145^{\circ}$ (Su-Sudeste).

Os resultados apontados na figura 04 foram extraídos dessas simulações exatamente para a porção submersa adjacente a cada ponto de monitoramento por perfis de praia ao longo da área de estudo.

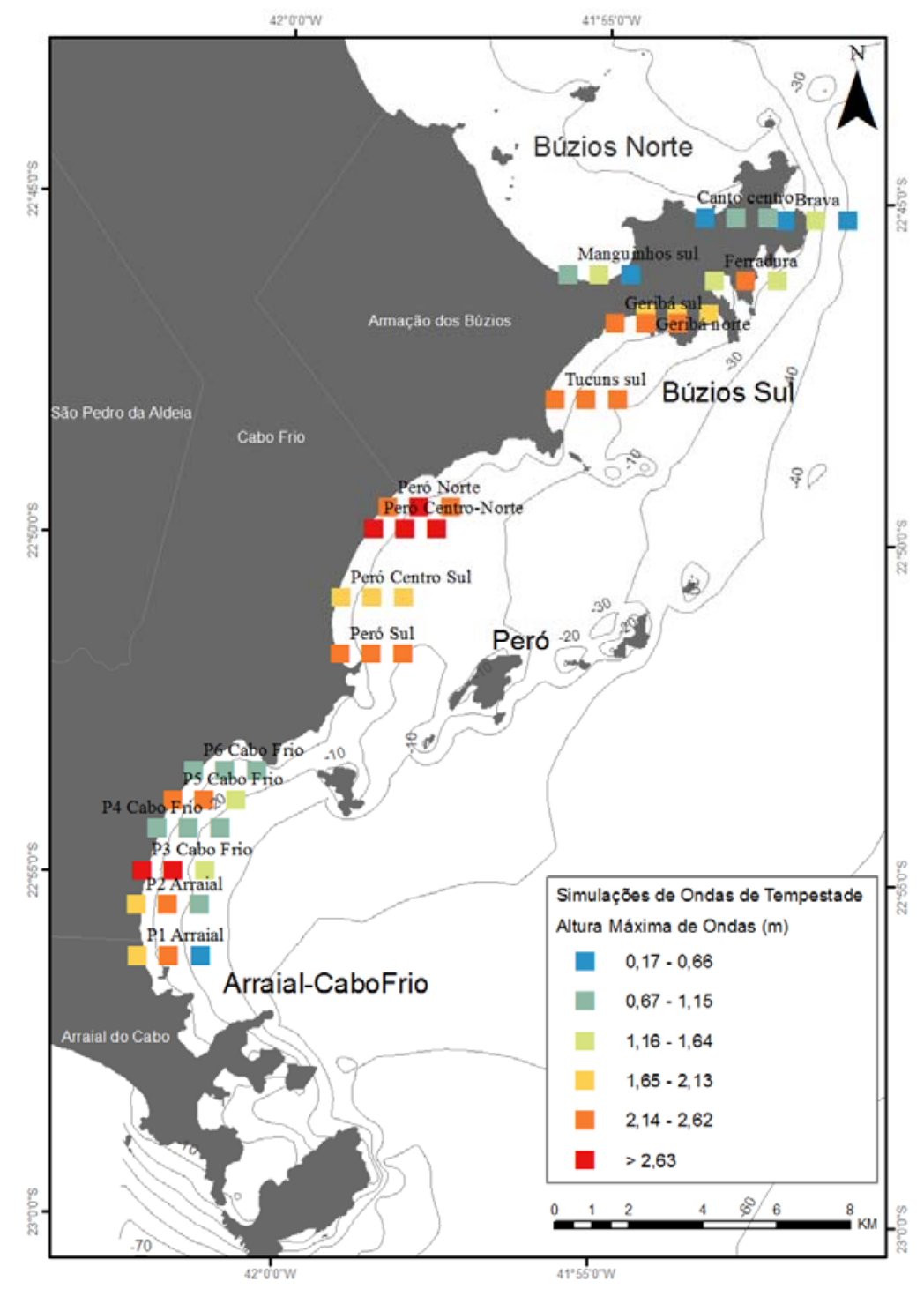

Figura 04: Resultados nos Perfis das Simulações de Ondas de Tempestade. Os quadrados representam da esquerda para a direita, as alturas máximas resultantes das simulações 01,02 e 03 respectivamente.

As maiores alturas máximas de ondas registradas para a posição dos perfis na área de estudo ocorreram na posição P3 (Cabo Frio), posição mais central do arco praial, para as simulações com entradas de ondas 
Papel da praia na proteção da costa e as alterações oceanográficas em diferentes escalas temporais

de Sul (simulação 01) e de Su-Sudeste (simulação 02). No arco praial Peró, a posição de perfil que recebe as maiores ondulações é o Peró Centro-Norte, para todas as simulações, algo também apontado por Muehe et al. (2010). Na área Búzios Sul, as posições Geribá Sul e Tucuns Sul recebem as maiores ondulações, dentro da mesma classe de ondas para quaisquer das direções simuladas.

Quanto às áreas protegidas das ondulações de tempestade, destaca-se inicialmente a área Búzios Norte, para todas as direções de ondas de tempestade protegidas pela difração que a projeção do Cabo Búzios faz frente às ondulações do quadrante Sul. Para as direções de ondas de tempestade de Su-Sudoeste (simulação 3), o arco praial Arraial-Cabo Frio recebe menor energia, quando comparado com as outras simulações.

Há um destaque também para a posição P6 Cabo Frio, a qual recebe, no perfil, as menores ondulações do arco praial para quaisquer que sejam as condições simuladas. De acordo com Pereira et al. (2008), a posição P6 tem características dissipativas, sendo a área preferencial de depósito de sedimentos transportados de sul para norte sob condições de tempestade e não remoção de frações sedimentares durante ondulações de tempo bom, em função da proteção exercida pela ponta da Lajinha, extremidade norte do arco. Estas características dissipativas promovem atenuação das ondas de tempestade para esta posição.

Há também uma posição de perfil simulada na posição central da Enseada da Ferradura que, apesar de se tratar de uma praia abrigada, torna-se exposta às ondulações de tempestade de Su-Sudeste, as quais promovem agitação intensa nesta posição da enseada.

Os resultados de uma forma geral mostram que a porção central e, em seguida, a porção norte dos arcos praiais recebem as maiores ondulações de tempestade, sendo a porção ao sul mais protegida.

\subsection{Variabilidade Volumétrica dos Perfis Subaéreos.}

Ao serem observadas as variações de volume nos perfis de praia levantados ao longo do arco praial Arraial-Cabo Frio (figura 05), constata-se que o perfil central (P3) é o mais estável e o perfil 05 o mais instável, notadamente apresentando seus menores volumes nos meses de outono/inverno (abril de 2005; agosto de 2010 e julho de 2012). Os picos de acumulação ocorreram nos meses de março de 2006 para o perfil $06\left(200 \mathrm{~m}^{3} / \mathrm{m}\right)$, outubro de 2007 para o perfil $05\left(192,5 \mathrm{~m}^{3} / \mathrm{m}\right)$, março de 2011 para o perfil 04 $\left(110,5 \mathrm{~m}^{3} / \mathrm{m}\right)$, fevereiro de 2012 para o perfil 03 $\left(55,71 \mathrm{~m}^{3} / \mathrm{m}\right)$, junho de 2006 para o perfil 02 $\left(156,5 \mathrm{~m}^{3} / \mathrm{m}\right)$ e abril de 2008 para o perfil 01 $\left(201 \mathrm{~m}^{3} / \mathrm{m}\right)$.

As maiores perdas no estoque sedimentar subaéreo neste arco praial ocorreram no perfil 06, posicionado mais ao norte do arco Arraial-Cabo Frio, entre os meses de abril de 2006 (205 $\left.\mathrm{m}^{3} / \mathrm{m}\right)$ e março de 2007 no perfil $06\left(116 \mathrm{~m}^{3} / \mathrm{m}\right)$, onde foram perdidos aproximados $43 \%$ do volume anterior. Nesses 11 meses, ocorreram 11 tempestades de acordo com a tabela 1, e sugere-se que, pelo efeito cumulativo, o perfil emerso não tenha se recuperado.

De uma forma geral, verifica-se que ao sul deste arco praial (perfis 01 e 02) ocorre depósito de sedimentos nos meses de tempestade (junho e abril), pois estas áreas são protegidas da incidência direta das ondas de tempestade destas ondulações. Já nos perfis da porção central e norte do arco praial (perfis 03 a 06), o acúmulo de sedimento é maior durante os meses em que a ocorrência das tempestades é menor.

A figura 06 mostra a variação volumétrica das quatro posições de perfis de praia estabelecidas ao longo do arco praial Peró. Os maiores ganhos (acumulação) ocorreram entre os meses de agosto de 2008 até maio de 2009 para o perfil Peró Centro Norte. Já entre os meses de maio de 2010 e março de 2011, houve ganho para todos os perfis. Nesse intervalo (10 meses), ocorreram apenas duas tempestades, fato que pode explicar o padrão cumulativo ao longo de todo o arco.

As maiores perdas ocorreram para o perfil Centro Norte, durante o período de um ano, entre maio de $2009\left(165 \mathrm{~m}^{3} / \mathrm{m}\right)$ e maio de $2010\left(91,98 \mathrm{~m}^{3} / \mathrm{m}\right)$, totalizando $73 \mathrm{~m}^{3} / \mathrm{m}$, quando ocorreram 10 eventos de tempestade. Nesse mesmo período, houve perdas contínuas no volume de sedimentos de todos os outros perfis, tendo o Peró Norte perdido $30,5 \mathrm{~m}^{3} / \mathrm{m}$, o Peró Sul $21,4 \mathrm{~m}^{3} / \mathrm{m}$ e o Peró Centro Sul $19 \mathrm{~m}^{3} / \mathrm{m}$. Cabe ressaltar que estas perdas corroboram o padrão de maior ou menor exposição às ondas de tempestade apresentadas na figura 04 .

Quanto à tendência geral, ao serem analisados 19 levantamentos para cada perfil, entre outubro de 2007 e março de 2013, observa-se que apenas a posição Peró Centro Sul apresenta tendência de queda no volume de sedimentos da porção subaérea do perfil, sendo todos os outros com tendência ao aumento no estoque de sedimentos ao longo do período, com flutuações sazonais, representando então não uma tendência global de erosão ou acumulação e sim a variabilidade morfodinâmica das praias do tipo intermediárias, concordando com o que Muehe et al. (2010) também apontaram para essa área. 
Papel da praia na proteção da costa e as alterações oceanográficas em diferentes escalas temporais

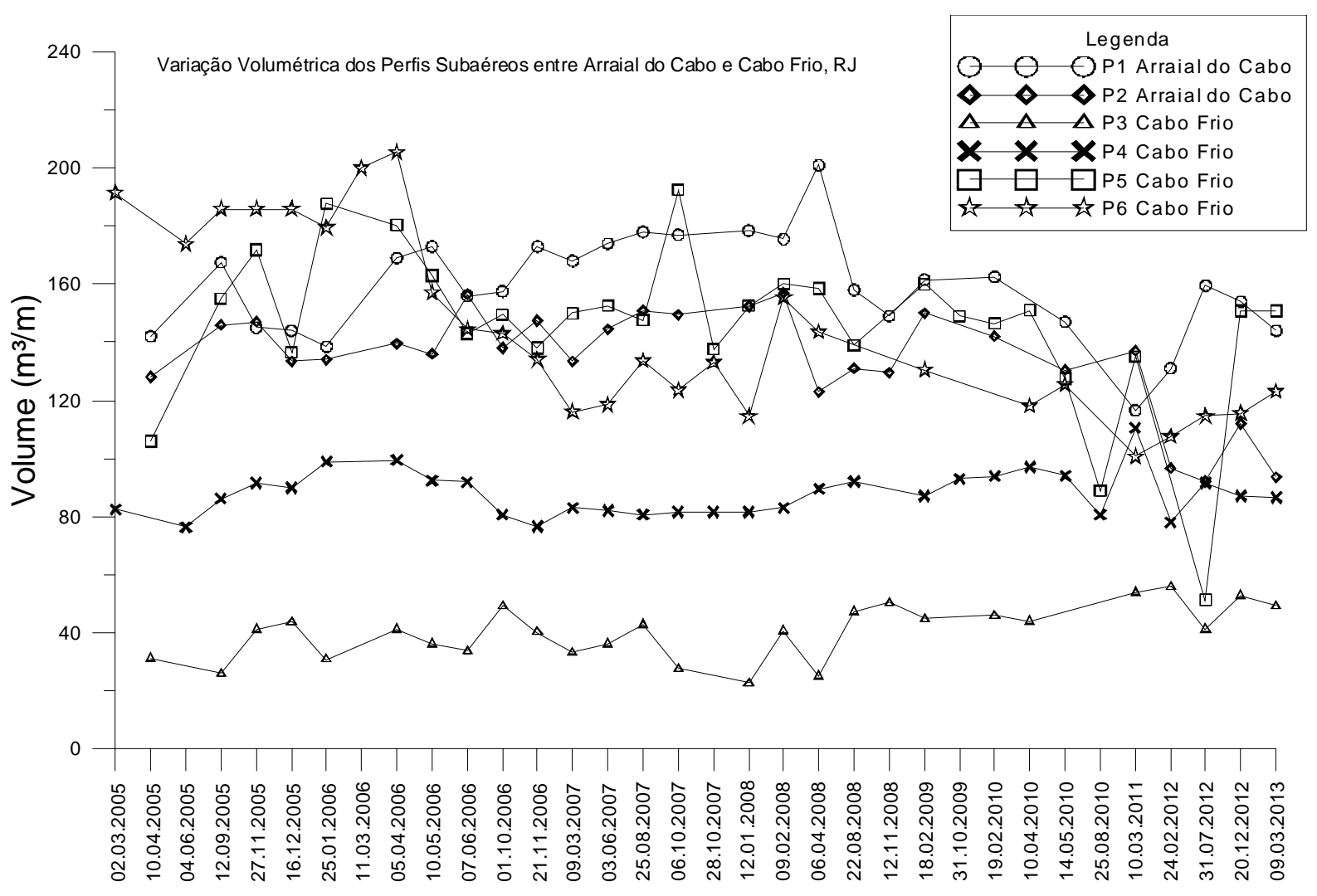

\section{Data do Levantamento}

Figura 05: Variação do Volume de Sedimentos na porção Subaérea dos Perfis estabelecidos no arco praial Arraial-Cabo Frio entre os meses de março de 2005 e março de 2013.

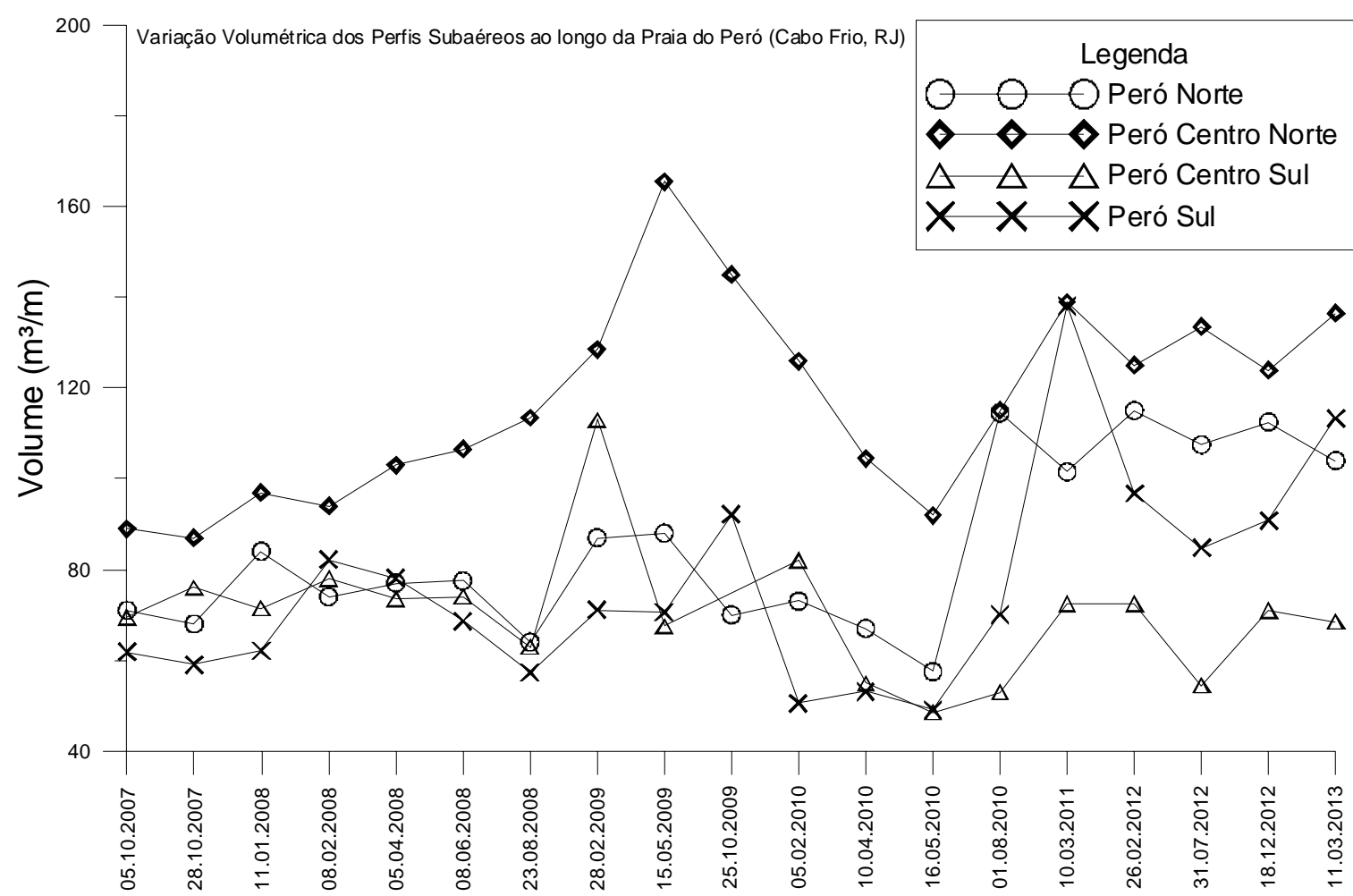

Data do Levantamento

Figura 06: Variação do Volume de Sedimentos na porção Subaérea dos Perfis estabelecidos no arco praial Peró entre os meses de maio de 2007 e março de 2013. 
Papel da praia na proteção da costa e as alterações oceanográficas em diferentes escalas temporais

Já a figura 07 apresenta a variação volumétrica de sete posições de perfis de praia selecionados nas enseadas do Cabo Búzios. O perfil Tucuns Sul apresenta a maior variabilidade volumétrica, acumulando uma perda significativa $\left(38 \mathrm{~m}^{3} / \mathrm{m}\right)$ entre janeiro e novembro de 2008, período em que 10 tempestades foram registradas. Entre fevereiro e maio de 2010, ocorreram apenas duas tempestades, sendo elas as de maior magnitude desde 2003 até o presente momento. Tal tempestade, cujos impactos morfológicos nas praias foram registrados em trabalhos de Bulhões et al. (2010) e Fernandez et al. (2011), promoveram perdas em todos os perfis da área Sul de Búzios, sendo $39 \mathrm{~m}^{3} / \mathrm{m}$ no perfil Geribá Norte; 7,4m³/m no perfil Geribá Sul; $19 \mathrm{~m}^{3} / \mathrm{m}$ no perfil Tucuns Sul; 5,5 $\mathrm{m}^{3} / \mathrm{m}$ no perfil Ferradura; e $1,5 \mathrm{~m}^{3} / \mathrm{m}$ no perfil Canto Centro. Quando essas variações são comparadas com o volume antecedente do perfil subaéreo, ele equivale a uma perda de, respectivamente, 73\%, 72\%, 22\%, 11\% e $33 \%$ do volume na porção subaérea desses perfis.

Nas áreas protegidas dos impactos de ondas de tempestade, ocorre o efeito contrário, ou seja, acumulação. Foram registradas acumulações de 5 m³/m no perfil Praia Brava, o que correspondeu à $24 \%$ do volume antecedente.

Os meses de verão são notadamente o período do ano em que as tempestades são escassas (tabela 1) e ocorrem tendências cumulativas nos perfis da porção Sul do Cabo Búzios. Ao se observar o período entre outubro de 2009 e fevereiro de 2010, nota-se um período cumulativo nos perfis Geribá Norte $\left(19,5 \mathrm{~m}^{3} / \mathrm{m}\right)$, Geribá Sul $\left(2,3 \mathrm{~m}^{3} / \mathrm{m}\right)$, Tucuns Sul $\left(54 \mathrm{~m}^{3} / \mathrm{m}\right)$ e Ferradura $\left(5 \mathrm{~m}^{3} / \mathrm{m}\right)$; ao passo que, nas posições expostas às ondas de tempo bom, ocorreram perdas no estoque sedimentar, como nos perfis Brava $\left(2 \mathrm{~m}^{3} / \mathrm{m}\right)$ e Manguinhos Sul $\left(45 \mathrm{~m}^{3} / \mathrm{m}\right)$.

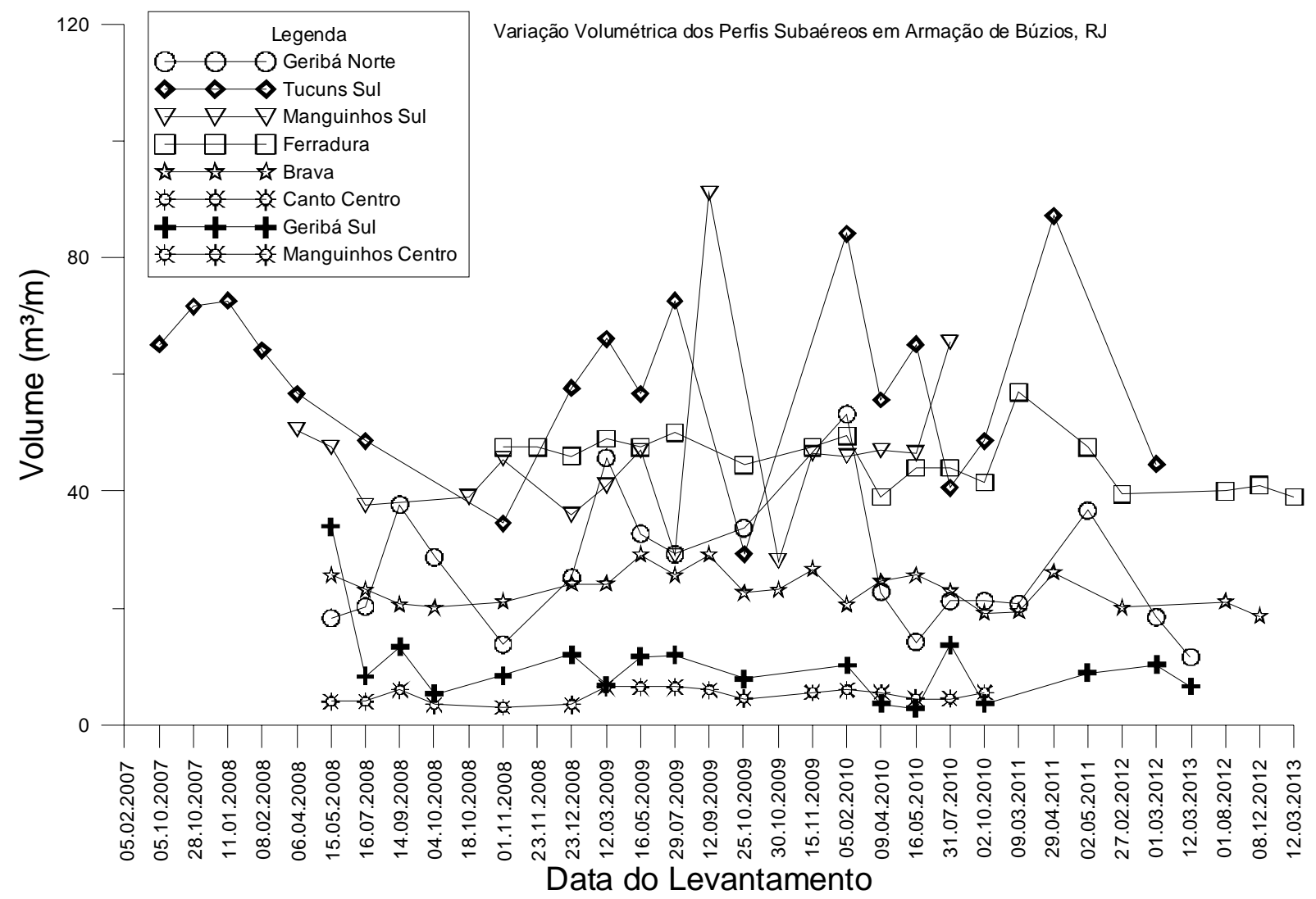

Figura 07: Variação do Volume de Sedimentos na porção Subaérea dos Perfis estabelecidos no arco praial Peró entre os meses de maio de 2007 e março de 2013.

\section{Conclusões}

Além das contribuições de autores citados ao longo do texto e do que foi apresentado como resultados, três tópicos podem ser apresentados como conclusivos neste trabalho:

- A distribuição granulométrica dos diâmetros médios das frações médias e grossas nas áreas de plataforma continental interna e antepraia adjacente à área de estudo aqui apresentada indica claramente que as áreas de maior energia hidrodinâmica estão localizadas na posição central dos arcos praiais. Apesar disso ser um excelente resultado, a interpretação da distribuição das areias finas e muito finas e das áreas preferenciais de erosão, transporte e deposição de sedimentos necessita da análise, dentre outros, dos parâmetros de dispersão como desvio padrão, assimetria e curtose, o que não foi o proposto neste trabalho.

- A distribuição de ondas de tempestade ao longo do tempo mostrou que o padrão interanual das tempestades ocorre entre os meses de abril e setembro (cerca de $80 \%$ ), o que pode ser chamado aqui de "temporada de 
Papel da praia na proteção da costa e as alterações oceanográficas em diferentes escalas temporais

ondas de tempestade”. Neste período a agitação oceânica é maior, com ondas que podem atingir 5 metros em águas profundas, majoritariamente ocorrendo entre as direções Su-Sudeste $\left(158^{\circ}\right)$ e Su-Sudoeste $\left(203^{\circ}\right)$, e ainda direciona maior energia para as porções centrais e norte dos arcos praiais entre o Cabo Frio e o Cabo Búzios. Assim, as posições ao Sul destes arcos permanecem mais protegidas. As enseadas e arcos praiais na porção Norte do Cabo Búzios são totalmente protegidas das ondas de tempestade e seus processos estão mais vinculados aos ventos de tempo bom, do quadrante Nordeste, e às vagas (seas) geradas, logo, esta área deve ser tratada como outro compartimento do litoral.

- A verificação da variabilidade do volume de sedimentos na porção subaérea dos perfis de praia, ao longo do tempo, mostra (de forma mais clara do que a sobreposição dos perfis topográficos) as oscilações dos agentes modeladores, neste caso, as ondas. Fica claro que durante a "temporada de ondas de tempestade” há uma tendência geral de perda no estoque de sedimentos da porção subaérea dos perfis posicionados, neste caso, para as direções preferenciais de entrada destas ondas, típica condição de "perfil de inverno". Fica claro também que, apesar dos estoques serem maiores ou menores em algumas posições, o volume das perdas acompanha a posição relativa dos perfis, sendo maiores naqueles mais expostos e menores naqueles mais protegidos das ondas de tempestade. A análise dos impactos morfológicos de ondas de tempestade pode ser subdividida em duas: a primeira análise deve considerar o "efeito cumulativo” que é ocasionado por um período de tempestades sucessivas (por exemplo 11 tempestades em 11 meses), já a segunda pode ser chamada de "efeito individual” e é o tipo de análise mais comum, como o caso citado do evento de abril de 2010. A medida que o número de levantamentos morfológicos nas praias vai se tornando maior, pode-se tentar entender este primeiro tipo de efeito e serem então apontadas tendências morfológicas do papel das praias na proteção à retroterra.

\section{Agradecimentos}

Os autores agradecem à FAPERJ e ao CNPq pela concessão de diárias para os levantamentos de campo e à CAPES pela concessão de bolsas de estudo durante a pós-graduação.

Os autores também agradecem aos inúmeros estudantes de graduação que colaboraram com os levantamentos de campo e com as análises em laboratório.

\section{Referências}

Bulhões E. 2011. Exposição de Praias, Clima de Ondas e Processos Físicos em Praias de Enseada: Exemplos e Aplicações em Armação dos Búzios, Rio de Janeiro, Brasil. Tese de Doutorado. Programa de Pós Graduação em Geologia e Geofísica Marinha. Universidade Federal Fluminense. 230p.

Bulhões E., Fernandez G.B. 2011. Analysis of shallow water wave propagation and coastal response in embayed beaches. case study in Cape Buzios, Rio de Janeiro, Brazil. Journal of Coastal Research, SI 64: 2022-2026.

Bulhões E., Fernandez G.B., Rocha T.B. 2010. Efeitos morfológicos nas barreiras costeiras do litoral centro-norte do estado do Rio de Janeiro: resultados do evento de tempestade de abril de 2010. Revista de Geografia da UFPE. Edição Especial SINAGEO 2010. Volume 2: 15-29.

Bulhões E., Fernandez G.B., Rocha T.B. 2013. Morphodynamics of embayed beaches. Case study in Cape Buzios, Rio de Janeiro, Brazil. SI 65:1739-1744.

Davis Jr R.A. 1985. Coastal Sedimentary Environments. Springer Verlag. New York. 716 p.

Dolan R.E., Davis R.E. 1992. An intensity scale for Atlantic northeast storms. Journal of Coastal Research, 8:352-364.

Fernandez G.B., Bulhões E., Rocha T.B. 2011. Impacts of severe storm occurred in April 2010 along Rio de Janeiro coast, Brazil. Journal of Coastal Research, SI 64:1850-1854.

Guerra J.V., Schmitt R.S., Souza J.H.M., Skrepnek C.C., Bentes A.M.L. 2005. Sedimentologia das praias arenosas da região costeira situada entre o Cabo Frio e o Cabo Búzios. X Congresso da Associação Brasileira dos Estudos do Quaternário.

Hallermeier R.J. 1981. A Profile Zonation for Seasonal Sand Beaches from Wave Climate. Coastal Engineering, 4:253-277.

Innocentini V., Arantes F.O., Prado S.C.C. 2003. Modelo de Ondas Aplicado ao Caso 5-8 de Maio de 2001. Revista Brasileira de Meteorologia, 18 (01): 97-104.

Jackson D.W.T., Cooper J.A.G., Del Rio L. 2005. Geological control of beach morphodynamic state. Marine Geology, 216: 297-314.

Jacob J., Gama C., Salgado R., Liu J.T., Silva A. 2009. Shadowing effects on beach morphodynamics during storm events on TróiaSines embayed coast, southwest Portugal. Journal of Coastal Research, SI 56: 73-77.

Johnson D.W. 1919. Shore Processes and Shoreline Development. John Wiley \& Sons, Inc. London, 584 p.

Komar P.D. 1976. Beach Processes and Sedimentation. Prentice Hall. New Jersey. 429 p.

Loureiro C., Ferreira Ó., Cooper J.A.G. 2009. Contrasting morphologic behaviour at embayed beaches in Southern Portugal. Journal of Coastal Research, 56:83-87.

Mahiques M.M., Tessler M.G., Furtado V.V. 1998. Characterization of energy gradient in enclosed bays of Ubatuba region, SouthEastern Brazil. Estuarine, Coastal and Shelf Science, 47:431446.

Morton R.A., Sallenger A.H. 2003. Morphological impacts of extreme storm on sandy beaches and barriers. Journal of Coastal Research, 19 (3):560-573.

Muehe D., Belligotti F.M., Lins-de Barros F.M., Oliveira J.F., Maia L.F.P.G. 2010. Potential vulnerability to climate change of the beach-dune system of the Peró coastal plain - Cabo Frio, Rio de Janeiro state, Brazil. Pan American Journal of Aquatic Sciences. 5(2):267-276.

Oliveira Filho S.R. 2011. Morfodinâmica Associada entre Duna, Praia e Zona Submarina como Subsídio a Adequada Ocupação do Espaço Costeiro na Praia do Peró - RJ. Dissertação de Mestrado. Centro de Ciências e Tecnologia. Área: Análise Geoambiental e Ordenação de Territórios de Regiões Semiáridas e Litorâneas, Universidade Estadual do Ceará. 96p.

Parise C.K. 2010. Estudo da Variabilidade de Ondas no Oceano Atlântico Sul e a Contribuição Energética de um Ciclone Extratropical Intenso nos Espectros das Ondas ao Largo do Rio Grande do Sul. Dissertação de Mestrado. Programa de Pós Graduação em Geociências. Universidade Federal do Rio Grande do Sul. 65p.

Parise C.K., Calliari L.J., Krusche N. 2009. Extreme storm surges in the South of Brazil: Atmospheric conditions and shore erosion. Brazilian Journal of Oceanography, 57(3):175-188. 
Papel da praia na proteção da costa e as alterações oceanográficas em diferentes escalas temporais

Pereira T.G. 2008. Geomorfologia e Morfodinâmica Costeira na Planície entre os Municípios de Cabo Frio e Arraial do Cabo, RJ. Dissertação de Mestrado. Programa de Pós-Graduação em Geologia e Geofísica Marinha. Universidade Federal Fluminense. $122 \mathrm{p}$.

Pereira T.G., Correa W.B., Rocha T.B., Fernandez G.B. 2008. Considerações sobre a morfodinâmica costeira e da morfologia submarina no arco de praia do Peró, litoral do Rio de Janeiro. VII Simpósio Nacional de Geomorfologia \& I Encontro LatinoAmericano de Geomorfologia.

Pereira T.G., Rocha T.B., Santos R.A., Fernandez G.B. 2007. Morfodinâmica entre a praia, duna e zona submarina adjacente nas proximidades do Cabo Frio, RJ. XI Congresso da Associação Brasileira dos Estudos do Quaternário.

Rangel-Buitrago N., Anfuso G. 2011. An application of Dolan and Davis (1992) classification to coastal storms in SW Spanish littoral. Journal of Coastal Research, SI 64:1891-1895.

Saavedra L (ver Filho). 1994. Dinâmica sedimentar na plataforma continental interna entre a Ilha do Cabo Frio e Cabo Búzios. Dissertação de Mestrado. Programa de Pós-Graduação em Geografia. Universidade Federal do Rio de Janeiro. 125 p.

Sahu B.K. 1964. Depositional mechanisms from the size analysis of clastic sediments. Journal of Sedimentary Petrology, 34(1):7383.

Sallenger A.H. 2000. Storm impact scale for barrier islands. Journal of Coastal Research, 16 (3):890-895.

Santiago I., Morichon D., Abadie S., Liria P., Epelde I. 2013. Effect of winter storms on a partly engineered embayed beach: The case of Zarautz beach (North of Spain). 2013. Coastal Dynamics 2013:487-498.

Satyamurty P., Mattos L.F. 1989. Climatological lower tropospheric frontogenesis in the midlatitudes due to horizontal deformation and divergence. Monthly Weather Review, 117:1355-1364.

Short A.D. 1999. Handbook of Beach and Shoreface Morphodynamics. John Wiley \& Sons Ltd. New York. 379 p.

Tavares A.C.A., Bulhões E., Estrada A.F.D. 2010. Distribuição de fácies sedimentares e tendências de transporte de sedimentos na enseada de Manguinhos, Armação dos Búzios, RJ. Revista de Geografia-Recife, 27 (2):81-97

Wentworth C.A. 1922. Scale of grade and class terms for clastic sediments. Journal of Geology, 30:377-392.

You Z.J., Lord D. 2008. Influence of the El-Niño-Southern Oscillation on NSW coastal storm severity. Journal of Coastal Research. 24(2A):203-207.

Recebido 09 de maio de 2014

Aceito 19 de novembro de 2014 